\title{
Improved recovery from limb ischaemia by delivery of an affinity- isolated heparan sulphate
}

\author{
Selina Poon ${ }^{1} \cdot$ Xiaohua Lu ${ }^{1} \cdot$ Raymond A. A. Smith ${ }^{1} \cdot$ Pei Ho$^{2} \cdot$ Kishore Bhakoo ${ }^{3,4,6} \cdot$ Victor Nurcombe $^{1,6}$. \\ Simon M. Cool ${ }^{1,5}$
}

Received: 20 September 2017 / Accepted: 8 May 2018 / Published online: 18 May 2018

(c) The Author(s) 2018

\begin{abstract}
Peripheral arterial disease is a major cause of limb loss and its prevalence is increasing worldwide. As most standard-of-care therapies yield only unsatisfactory outcomes, more options are needed. Recent cell- and molecular-based therapies that have aimed to modulate vascular endothelial growth factor-165 $\left(\mathrm{VEGF}_{165}\right)$ levels have not yet been approved for clinical use due to their uncertain side effects. We have previously reported a heparan sulphate (termed HS7) tuned to avidly bind VEGF 165 . Here, we investigated the ability of HS7 to promote vascular recovery in a murine hindlimb vascular ischaemia model. HS7 stabilised VEGF $_{165}$ against thermal and enzyme degradation in vitro, and isolated VEGF $_{165}$ from serum via affinitychromatography. C57BL6 mice subjected to unilateral hindlimb ischaemia injury received daily intramuscular injections of respective treatments $(n=8)$ and were assessed over 3 weeks by laser Doppler perfusion, magnetic resonance angiography, histology and the regain of function. Mice receiving HS7 showed improved blood reperfusion in the footpad by day 7. In addition, they recovered hindlimb blood volume two- to fourfold faster compared to the saline group; the greatest rate of recovery was observed in the first week. Notably, 17\% of HS7-treated animals recovered full hindlimb function by day 7, a number that grew to $58 \%$ and $100 \%$ by days 14 and 21 , respectively. This was in contrast to only $38 \%$ in the control animals. These results highlight the potential of purified glycosaminoglycan fractions for clinical use following vascular insult, and confirm the importance of harnessing the activity of endogenous pro-healing factors generated at injury sites.
\end{abstract}

Keywords Angiogenesis · VEGF · Blood vessel formation · Glycosaminoglycan · Vascular insufficiency

\section{Introduction}

Electronic supplementary material The online version of this article (https://doi.org/10.1007/s10456-018-9622-9) contains supplementary material, which is available to authorized users.

Simon M. Cool

simon.cool@imb.a-star.edu.sg

1 Glycotherapeutics Group, Institute of Medical Biology, Agency for Science, Technology and Research, 8A Biomedical Grove, Immunos \#06-06, Singapore 138648, Singapore

2 Department of Surgery, Yong Loo Lin School of Medicine, NUS and Department of Cardiac, Thoracic, Vascular Surgery, National University Health System, Singapore, Singapore

3 Translational Molecular Imaging Group, Singapore Bioimaging Consortium, Agency for Science, Technology and Research, Singapore, Singapore
Vascular insufficiency affects one in ten people over 70 years of age and one in six over 80 [1]. With age as a major contributing factor, the number of people diagnosed with peripheral arterial disease (PAD) increased by over $23 \%$ in

4 Department of Biochemistry, Yong Loo Lin School of Medicine, National University of Singapore, Singapore, Singapore

5 Department of Orthopaedic Surgery, Yong Loo Lin School of Medicine, National University of Singapore, Singapore, Singapore

6 Lee Kong Chian School of Medicine, Nanyang Technology University - Imperial College London, Singapore, Singapore 
the decade between 2000 and 2010 [1]. Current treatment options include either changes in lifestyle for patients experiencing intermittent claudication or surgical intervention such as open surgical bypass or catheter-based revascularization for patients at risk of limb loss. With concerns growing around the long-term patency of surgical procedures [2], and the ongoing failure of procedural revascularization in a significant proportion of patients [3], clinicians are also focusing efforts on alternative strategies. Novel attempts to induce new vessel formation at sites of tissue ischaemia have concentrated on the use of $\mathrm{O}_{2}$ therapy [4], stem cell [5] or growth factor therapy [6]. They all aim to increase the local concentration of growth factors to stimulate angiogenesis. More recently, restoring balance in the glycosaminoglycan (GAG) fraction of vessel extracellular matrix (ECM) has proven effective for the induction of new vessels in embryonic models [7]. Such GAG-based treatments are novel because they act by sequestering, and then bio-activating powerful endogenous mitogens naturally produced at sites of tissue ischaemia to promote the formation of new vessels, all without the risks inherent with exogenous growth factor therapy.

Angiogenesis is a complex process that involves temporal regulation of growth factor signalling to initiate neovascularization and remodelling at the compromised site. The most actively studied growth factor for angiogenic therapy has been vascular endothelial growth factor-A (VEGF-A) [8]. Neovascularization in the ischaemic limb can be attenuated with the use of neutralising antibodies against VEGF [9], highlighting its critical role during vessel recovery in the early stages of revascularization. Most investigations have focused on the 165-isoform of VEGF-A $\left(\mathrm{VEGF}_{165}\right)$ due to its intrinsic potency. While the use of VEGF-A has proven successful for treating ischaemia in animal models [10], only modest benefits have been reported in human clinical trials [11], mainly owing to the short half-life of the growth factor $[12,13]$ when confronted with fluctuations in inflammatory state, $\mathrm{pH}$, temperature, oxidation states and proteolytic factors within sites of damage [14]. In attempts to overcome the poor pharmacokinetics, multiple large doses of growth factors are frequently administered, which often result in unwanted toxicity and adverse off-target events [15].

The binding of VEGF to receptors on endothelial cells to initiate the angiogenesis cascade [16] is dependent on particular forms of its carbohydrate cofactor, heparan sulphate (HS) [17]. Such a crucial role suggests the possibility of developing these sugars for angiogenic therapy. However, targeting the binding of HS to particular proteins is necessary for driving desirable outcomes, because the inherent heterogeneity of pericellular HS leads to the binding of a plethora of factors that can otherwise disrupt angiogenic progression. We previously reported a $\mathrm{VEGF}_{165}$-binding HS (HS7) that was isolated via affinity-chromatography using the heparin-binding domain of $\mathrm{VEGF}_{165}$ as an affinity substrate [18]. HS7 demonstrated increased affinity for VEGF $_{165}$ and potentiated endothelial cell proliferation and vessel tube formation in an embryonic model. The most striking observation was the ability of HS7 alone to promote blood vessel formation in the chick embryo chorioallantoic membrane assay without the addition of exogenous VEGF $_{165}$ [18]. Here, we sought to determine whether $\mathrm{VEGF}_{165}$ could be protected from thermal and enzymatic degradation by HS7. In a hypoxic environment, where VEGF expression is elevated to promote angiogenesis and reperfusion of blood supply to the injured site, one of the factors determining the extent of the angiogenic response is its stability. VEGF is very susceptible to both thermal and enzymatic degradation in vivo. Brandner et al. have previously demonstrated that VEGF can be protected against thermal degradation by heparin [19].

To further exemplify the proangiogenic potential of HS7, we induced hindlimb ischaemia in mice and investigated the ability of HS7 to restore blood flow. Our results demonstrate that HS7 by itself can restore blood volume at ischaemic sites by increasing blood vessel density. The results support the continued development of glycosaminoglycans as a means of therapeutic angiogenesis.

\section{Methods}

\section{Materials}

HS7 used in this paper was isolated from crude porcine mucosal HS (HS ${ }^{\mathrm{pm}}$, Lot\# HO-10697; Celsus Laboratories, Cincinnati, $\mathrm{OH}$ ) using the methods previously described [18]. Recombinant human VEGF $_{165}\left(\mathrm{VEGF}_{165}\right)$ and Tolllike receptor-4 (TLR4), and biotinylated antibody against VEGF $_{165}$ were from R\&D Systems (Minneapolis, MN). Horseradish peroxidase (HRP)-conjugated streptavidin was from Invitrogen. Plasmin, general chemicals and reagents were purchased from Sigma-Aldrich. Human umbilical vein endothelial cells (HUVECs) (Merck Millipore) were provided at passage 1 and maintained with the EndoGRO ${ }^{\mathrm{TM}}$ Low Serum culture media kit (Merck Millipore). HUVECs from passages $2-8$ were used for all experiments.

\section{Thermal degradation and plasmin proteolysis}

To investigate thermal stability, $5.2 \mathrm{mmol} / \mathrm{L} \mathrm{VEGF}_{165}$ was pre-incubated with or without respective $\mathrm{HS}(1 \mu \mathrm{g} / \mu \mathrm{l})$ on ice for $10 \mathrm{~min}$. The reactions were then transferred to $37^{\circ} \mathrm{C}$ for further incubation, or $-80{ }^{\circ} \mathrm{C}$ for subsequent freeze-thaw treatment. For reactions incubated at $37^{\circ} \mathrm{C}$, aliquots of each reaction were collected at stipulated time points and stored at $-80{ }^{\circ} \mathrm{C}$. 
In addition to thermal degradation, $\mathrm{VEGF}_{165}$ is also susceptible to enzymatic digest by plasmin in vivo. To determine the stability of $\mathrm{VEGF}_{165}$ against plasmin digest, $5.2 \mathrm{mmol} / \mathrm{L} \mathrm{VEGF}_{165}$ was pre-incubated on ice for $10 \mathrm{~min}$ with or without respective HS $(1 \mu \mathrm{g} / \mu \mathrm{L})$. Plasmin was added to the reactions (final activity $0.5 \mathrm{mU} / \mu \mathrm{L}$ ) and then further incubated for $4 \mathrm{~h}$ at $37^{\circ} \mathrm{C}$.

At the end of the respective assays, $4 \times$ native gel loading buffer $(40 \mathrm{mmol} / \mathrm{L}$ Tris- $\mathrm{HCl} \mathrm{pH} 8,400 \mathrm{mmol} / \mathrm{L} \mathrm{KCl}, 40 \%$ $v / v$ glycerol, $0.4 \% v / v$ NP-40) was added to the thermal and proteolytic degradation reactions, resolved on 4-12\% BisTris gelsNuPAGE, Novex, Life Technologies) and blotted onto nitrocellulose membranes. Membranes were blocked and incubated with a biotinylated anti-VEGF antibody, followed by HRP-conjugated streptavidin. Immunoreactive bands were visualised using the LumiGLO ${ }^{\circledR}$ Chemiluminescent Substrate Kit.

\section{VEGF-VEGFR2 signal transduction}

HUVECs were seeded in 12-well plates at a density of 190,000 cells per well and cultured in EndoGRO ${ }^{\text {TM }}$-Low Serum complete culture media kit lacking HS, rEGF and LS-growth supplement for $24 \mathrm{~h} . \mathrm{VEGF}_{165}$ (treated as described in Thermal degradation and plasmin proteolysis) was added to cells and incubated for $10 \mathrm{~min}$ at $37^{\circ} \mathrm{C}$. Cells were washed with ice-cold $1 \times$ PBS and lysed in ice-cold RIPA lysis buffer containing protease inhibitor cocktail and $2 \mathrm{mmol} / \mathrm{L}$ sodium orthovanadate. The lysate was collected and incubated on ice for $20 \mathrm{~min}$ and clarified. Total protein content was determined using the BCA quantification method with the Pierce ${ }^{\mathrm{TM}}$ BCA Protein Assay Kit (Thermo Scientific). For each reaction, $10 \mu \mathrm{g}$ of protein was resolved on 4-12\% Bis-Tris gels under reducing conditions and blotted onto nitrocellulose membranes. Membranes were subsequently blocked and probed with specific primary antibodies (Cell Signaling Technology Inc.) followed by appropriate HRP-conjugated secondary antibodies (Jackson Immunoresearch). Immunoreactive bands were visualised using the LumiGLO ${ }^{\circledR}$ Chemiluminescent Substrate Kit (KPL, USA).

\section{Cell proliferation}

The BrdU Cell Proliferation Kit (Roche) was used to assay cell proliferation. HUVECs were seeded in 96-well plates at a density of 50 cells $/ \mathrm{mm}^{2}$ (square millimetre) and cultured in EndoGRO ${ }^{\text {TM-Low }}$ Serum complete culture media kit lacking HS, rhEGF and LS-growth supplement for $24 \mathrm{~h}$. VEGF $\mathrm{V}_{165}$ (treated as described in Thermal degradation and plasmin proteolysis) was added to cells and incubated at $37^{\circ} \mathrm{C}$. After $24 \mathrm{~h}, \mathrm{BrdU}$ was added to cells and incorporated for $24 \mathrm{~h}$. BrdU detection was performed according to the manufacturer's protocol.

\section{Affinity fractionation using HS-tagged chromatography columns}

The interaction of HS with growth factors in serum was investigated using a modified affinity fractionation protocol. To prepare the column, lyophilised cyanogen bromideactivated Sepharose 4B (CNBr-Sepharose) (GE Healthcare) was rehydrated in $1 \mathrm{mmol} / \mathrm{L} \mathrm{HCl}$. The $\mathrm{CNBr}$-Sepharose slurry was incubated with HS in binding buffer $(100 \mathrm{mmol} / \mathrm{L}$ $\mathrm{NaHCO}_{3}, 500 \mathrm{mmol} / \mathrm{L} \mathrm{NaCl}, \mathrm{pH} 8.3$ ) at a ratio of 2:1 $\mathrm{HS}$ to $\mathrm{CNBr}$-Sepharose to obtain HS-tagged Sepharose beads that were loaded onto chromatography columns and washed with wash buffer $(1 \times \mathrm{PBS}, 1 \mathrm{~mol} / \mathrm{L} \mathrm{NaCl})$, followed by equilibration buffer $(50 \mathrm{mmol} / \mathrm{L}$ Tris, $200 \mathrm{mmol} / \mathrm{L} \mathrm{NaCl}, 2 \mathrm{mmol} / \mathrm{L}$ $\mathrm{CaCl}_{2}, 2 \mathrm{mmol} / \mathrm{L} \mathrm{MgCl}_{2}, \mathrm{pH}$ 7.4). The fractionation sample was prepared by adding $500 \mathrm{ng} \mathrm{VEGF}_{165}$ and $500 \mathrm{ng}$ BMP-2 (bone morphogenetic protein-2) to fetal bovine serum (FBS), then diluted in equilibration buffer. The samples were added to the columns (HS7-tagged or $\mathrm{HS}^{\mathrm{ft}}$-tagged columns) and washed with equilibration buffer via gravity-flow. A first elution was done using Elution Buffer $1(50 \mathrm{mmol} / \mathrm{L}$ Tris, $500 \mathrm{mmol} / \mathrm{L} \mathrm{NaCl}, 2 \mathrm{mmol} / \mathrm{L} \mathrm{CaCl}_{2}, 2 \mathrm{mmol} / \mathrm{L} \mathrm{MgCl}_{2}, \mathrm{pH}$ 7.4) to remove weak binding proteins to the HS-tagged column. A second elution was then performed using Elution Buffer $2\left(50 \mathrm{mmol} / \mathrm{L}\right.$ Tris, $1 \mathrm{~mol} / \mathrm{L} \mathrm{NaCl}, 2 \mathrm{mmol} / \mathrm{L} \mathrm{CaCl}_{2}$, $2 \mathrm{mmol} / \mathrm{L} \mathrm{MgCl}_{2}, \mathrm{pH}$ 7.4) to elute proteins that firmly bound to the column. Samples eluted with Elution Buffer 2 were prepared for immunoblotting as previously described using native gel loading buffer.

\section{Surface-plasmon resonance (SPR)-based measurement of protein binding to heparin-coated SA sensor chip}

Protein binding to a streptavidin (SA) sensor chip was performed as previously described [18]. Briefly, biotinylated heparin was immobilised onto a streptavidin (SA) sensor chip. Protein binding to the heparin support was detected using a BIACORE T100 surface-plasmon resonance instrument as per the manufacturer's protocols (GE Healthcare, Sweden). Toll-like receptor 4 (TLR4) was prepared in HBSEP running buffer (10 mM HEPES, $150 \mathrm{mM} \mathrm{NaCl}, 0.1 \%$ $v / v$ Tween-20) and applied to the sensor chip at a flow rate of $30 \mu \mathrm{L} / \mathrm{min}$ for $120 \mathrm{~s}$, followed by washing with running buffer for $600 \mathrm{~s}$. The sensor chip was regenerated between consecutive applications of TLR4 at different concentrations. VEGF 165 was applied separately as a comparison.

\section{Signal transduction in RAW264.7}

RAW264.7 cells were cultured in Dulbecco's Modified Eagle Medium (DMEM, high glucose, pyruvate preparation, Gibco ${ }^{\mathrm{TM}}$, Thermo Fisher Scientific) supplemented 
with $10 \% v / v$ FBS and $100 \mu \mathrm{g} / \mathrm{mL}$ streptomycin and $100 \mathrm{IU} / \mathrm{mL}$ penicillin. For signal transduction, RAW264.7 were seeded in 6-well plates at a density of $2 \times 10^{6}$ cells per well. Lipopolysaccharide (LPS) at $50 \mathrm{ng} / \mathrm{mL}$, or HS at $10 \mu \mathrm{g} / \mathrm{mL}$ were added to cells and incubated for $20 \mathrm{~min}$ at $37^{\circ} \mathrm{C}$. Cells were then washed and lysate was collected and quantified as described in the section on "VEGFVEGFR2 signal transduction". For each treatment condition, $20 \mu \mathrm{g}$ of lysate was resolved on $4-12 \%$ Bis-Tris gels under reducing conditions, blotted onto nitrocellulose membranes, and probed with specific antibodies followed by appropriate HRP-conjugated secondary antibodies. Immunoreactive bands were visualised using the LumiGLO ${ }^{\circledR}$ Chemiluminescent Substrate Kit.

\section{Efficacy study of HS7 in murine model of hindlimb ischaemia}

All animal-related procedures were in accordance with Institutional Animal Care and Use Committee guidelines at the Biological Resource Centre, A*STAR, Singapore (IACUC \#130842). Unilateral hindlimb ischaemia was induced in the right hindlimb of C57BL/6N mice (male, 10 weeks old, each weighing 20-25 g) as described previously [20]. Male mice were chosen to exclude the effect of hormonal influences in the angiogenic healing response. Also, the C57BL/6 strain was shown to exhibit elevated expression of the murine VEGF-A-164 isoform following ischaemia, which shares $89 \%$ homology with corresponding regions of human $\mathrm{VEGF}_{165}$ and could stimulate HUVEC proliferation $[8,9]$. Briefly, the mice were anaesthetised with an intraperitoneal injection of Ketamine $(150 \mathrm{mg} / \mathrm{kg})$ and Xylazine $(10 \mathrm{mg} / \mathrm{kg})$. A $1-\mathrm{cm}$ incision was made in the right hindlimb from the medial thigh to the knee. The external iliac artery was isolated, ligated twice using 7/0 polypropylene suture (Premilene, Braun, Melsungen AG) and then transected between the two ligations. The mice received subcutaneous injections of Enrofloxacin $(10 \mathrm{mg} /$ $\mathrm{kg})$ once daily for 5 days and of Buprenorphine $(0.1 \mathrm{mg} /$ $\mathrm{kg}$ ) twice daily for 3 days after the surgery. The animals were divided into four treatment groups. One day after surgery and for a further 7 days, animals were injected daily with $3 \mu \mathrm{g}$ HS7 $(n=8), 30 \mu \mathrm{g} \operatorname{HS} 7(n=8)$ or $30 \mu \mathrm{g}$ flowthrough $\mathrm{HS}\left(\mathrm{HS}^{\mathrm{ft}}, n=8\right)$ intramuscularly at three different sites on the operated limb (vastus lateralis, vastus medialis and gastrocnemius). All HSs were delivered in $60 \mu \mathrm{L}$ of PBS. Controls $(n=8)$ received PBS $(60 \mu \mathrm{L})$ only. Postoperative loss and gain of function, during the treatment and recovery phases were recorded and categorised numerically from 1 to 4 , with 1 showing loss of function and 4 showing recovery of function (Table 1). A list of animals is shown in the Supplemental Table (Table S1).
Table 1 Hindlimb functional score

\begin{tabular}{ll}
\hline 4 & Full recovery \\
3 & Able to flex toes, but lacks fine motor control \\
2 & Able to support weight on the hindlimb \\
1 & Dragging hindlimb \\
\hline
\end{tabular}

\section{Laser Doppler flow imaging (LDI)}

Blood perfusion in the plantar foot was assessed using a PeriScan PIM 3 laser Doppler system (Perimed AB, Sweden) preoperatively, postoperatively and on days $3,7,14$ and 21 . Animals were anaesthetised with $2 \%$ isoflurane and placed in a prone position connected to a continuous flow of isoflurane (1-3\%) for the duration of the scan. Images were analysed using PIMSoft software (Perimed AB, Sweden). The footpad was used as the region of interest; the perfusion rate in the footpad of the right (ligated) limb was normalised to the contralateral (non-ligated) limb.

\section{Magnetic resonance angiography (MRA)}

The hindlimb vasculature of the animals was acquired using time-of-flight (TOF) magnetic resonance angiography (MRA) with a Bruker Biospec 9.4T scanner (Bruker, Germany). A flow compensated gradient-echo TOF protocol, with a spatial resolution of 0.109 millimetres per pixel $(\mathrm{mm} /$ pixel $) \times 0.109 \mathrm{~mm} /$ pixel, $0.35 \mathrm{~mm}$ slice thickness and 150 slices, was applied at ultra-high field to characterise the vascular signal above the signals originating from the surrounding stationary tissues. Signals originating from the stationary tissues were saturated with very short repetition time such that the longitudinal magnetization of these tissues did not have time to recover, thereby weakening their signal. This favours the inflow effect.

The MRA data were analysed using ImageJ software. Blood vessels were segmented by thresholding. The total volume of blood was calculated by multiplying the total vessel area by the slice thickness. 80 slices covering the start of the thigh to the lower calf were used for blood volume quantification. Image slices were stacked using Onis 2.5 (DigitalCore Co. Ltd., Japan) to create three-dimensional views of the vasculature.

\section{Immunohistochemistry and histomorphometric analysis}

Quadriceps, hamstring and gastrocnemius tissues were harvested on day 8 post-surgery. Tissues were fixed in $10 \%$ neutral buffered formalin and embedded in paraffin. Serial transverse sections from all tissues were obtained and stained for visualisation of von Willebrand factor (vWF) with rabbit 
anti-human vWF antibody (Dako, USA) using the LEICA Bond Auto Stain according to the manufacturer's instructions, and also for haemotoxylin and eosin (H\&E) staining for visualisation of muscle morphology. Transverse sections from quadriceps tissue were obtained and stained for visualisation of $\alpha$-smooth muscle actin ( $\alpha \mathrm{SMA})$ using rabbit anti- $\alpha$ SMA antibody (Abcam, Catalogue ab5694) following standard immunohistochemistry protocols. Images for quantification of vWF-stained and $\alpha$ SMA-stained vessels were captured under brightfield using the Metafer 4 automated captured system (MetaSystems, Germany). Vessels positive for $v W F$ and $\alpha$ SMA were counted from six random fields of view per section and represented as the number of vWF-positive $\left(\mathrm{vWF}^{+}\right)$or $\alpha \mathrm{SMA}^{+}$cells \pm standard deviation per square millimetre of area quantified. For display purposes only, representative images were captured on the ZEISS AxioImage Z1 (ZEISS, Germany) and uniform adjustments were made on ImageJ to enhance contrast. The number of regenerating myofibres, defined as having a centrally located nuclei [21], was counted from H\&E sections. Data were presented as the mean number of regenerating myofibres \pm standard deviation per square millimetre of area quantified. All measurements were made on unprocessed images.

\section{Statistical analysis}

Data on proliferation were reported as the mean \pm standard deviation of three independent experiments. Data on LDI and MRA were reported as the mean fold-change \pm standard deviation. Statistical analyses were performed with GraphPad Prism 7.0a (GraphPad Software Inc., San Diego, CA). Unpaired $t$ test, or one-way and two-way ANOVA with Tukey's multiple comparisons were performed where appropriate.

\section{Results}

\section{Growth factor stability}

To assess the ability of HS fractions to maintain the stability of VEGF $_{165}$ at physiological temperature, we incubated VEGF $_{165}$ with or without HS variants at $37^{\circ} \mathrm{C}$ and then tested for the presence of the native, homodimeric $\mathrm{VEGF}_{165}$ by immunoblotting. In the absence of HS, the amount of homodimeric, $\sim 38 \mathrm{kDa} \mathrm{VEGF}_{165}$, declined rapidly over time and was no longer detectable within $30 \mathrm{~min}$ (Fig. 1a). In contrast, VEGF 165 incubated with $\mathrm{HS} 7$ at $37{ }^{\circ} \mathrm{C}$ remained detectable at all time points examined (up to $6 \mathrm{~h}$ ). In comparison, depleted $\mathrm{HS}^{\mathrm{ft}}$ was only able to maximally protect $\mathrm{VEGF}_{165}$ for the first $60 \mathrm{~min}$.

Growth factors are susceptible to enzyme proteolysis in vivo, with VEGF $_{165}$ particularly vulnerable to digestion by plasmin, an enzyme present in blood that is responsible for clot dissolution and extracellular matrix protein degradation [22]. The plasmin cleavage of $\mathrm{VEGF}_{165}$ removes its heparin-binding domain, the basic region that gives the growth factor the ability to interact with endogenous HS [23]. We, therefore, investigated the ability of HS variants to protect $\mathrm{VEGF}_{165}$ from proteolysis by plasmin.

Under non-reducing conditions, intact $\mathrm{VEGF}_{165}$ migrated to its predicted $38 \mathrm{kDa}$ (Fig. 1b, first lane). Plasmin cleavage of $\mathrm{VEGF}_{165}$ gave rise to two additional bands at approximately 30 and $25 \mathrm{kDa}$ (Fig. $1 \mathrm{~b}$, second lane). These corresponded to the $\mathrm{VEGF}_{165} / \mathrm{VEGF}_{110}$ heterodimer and $\mathrm{VEGF}_{110}$ homodimer, respectively (Fig. 1b). In the absence of HS, there was a decreased amount of $\mathrm{VEGF}_{165}$ homodimer detected after plasmin digest; in contrast, the VEGF $_{165}$ homodimer was strongly detected after plasmin digest in the presence of HS7. Furthermore, there was considerably more $\mathrm{VEGF}_{165}$ homodimer present when incubated with HS7 than with $\mathrm{HS}^{\mathrm{ft}}$.

\section{Signal transduction and proliferation}

Protein denaturation and enzymatic proteolysis lead to a loss of biological activity. To investigate whether HS7 was able to maintain the biological activity of $\mathrm{VEGF}_{165}$ after a denaturing or proteolytic event, VEGF $_{165}$ pre-complexed with HS variants was subjected to a freeze-thaw cycle or plasmin proteolysis, and then used to challenge HUVECs. Under native conditions (the absence of freeze-thaw or plasmin proteolysis), signal transduction induced by VEGF $_{165}$ led to increased VEGF receptor-2 and ERK1/2 phosphorylation (Fig. 1c). Complexing VEGF $_{165}$ with HS7 before freeze-thaw or plasmin proteolysis maintained VEGF $_{165}$ signal transduction activity when compared to VEGF $_{165}$ alone (Fig. 1d, e, respectively). The level of phosphorylation induced by $\mathrm{VEGF}_{165}$ was also increased in the presence of HS7 compared to $\mathrm{HS}^{\mathrm{ft}}$ (Fig. 1d, e, respectively), an observation consistent with a previous report [18].

The ability of HS7 to stabilise $\mathrm{VEGF}_{165}$ against thermal or proteolytic denaturation was further investigated with a proliferation assay. Similar for signal transduction, $\mathrm{VEGF}_{165}$, freeze-thawed or plasmin-digested in the presence or absence of HS variants, was added to cells and proliferation measured by BrdU incorporation. Both thermal and plasmin exposure reduced the bioactivity of $\mathrm{VEGF}_{165}$ compared to native $\operatorname{VEGF}_{165}$ (Fig. 1f). In the presence of HS7, VEGF 165 exerted greater proliferative effects on HUVECs, which was in contrast to the HS7-depleted HS ${ }^{\mathrm{ft}}$ (Fig. 1f, $p<0.01$ and $p<0.05$, respectively). 
Fig. 1 In vitro analyses of HS7 activity a Thermal degradation of $\mathrm{VEGF}_{165}$ complexed with HS variants. Representative immunoblots showing the degradation of VEGF ${ }_{165}$ complexed with HS variants over time at $37^{\circ} \mathrm{C}$. b Representative immunoblot showing plasmin proteolysis of VEGF $_{165}$ complexed with HS variants for $4 \mathrm{~h}$ at $37^{\circ} \mathrm{C}$. The schematic diagram to the right of the immunoblot shows the VEGF $_{165}$ homodimer, VEGF $_{165}$ / VEGF $_{110}$ heterodimer and VEGF $_{110}$ homodimer, and the approximate molecular weights they resolve to via polyacrylamide gel electrophoresis: 38 , 30 and $25 \mathrm{kDa}$, respectively. The plasmin cleavage sites are indicated by arrows. Signal transduction in HUVECs induced by $\mathbf{c}$ native $\mathrm{VEGF}_{165}$, d freeze-thawed HS/VEGF ${ }_{165}$ complexes, or e plasmindigested HS/VEGF ${ }_{165}$ complexes. f HUVEC proliferation stimulated by native, freezethawed or plasmin-digested HS/ VEGF $_{165}$ complexes. Immunoblots shown are representative of three independent experiments. Data for BrdU incorporation are represented as mean \pm SD of fold-change calculated from three independent experiments. One-way ANOVA with Tukey's multiple comparisons test was performed $(* p<0.05$; $* * p<0.01)$
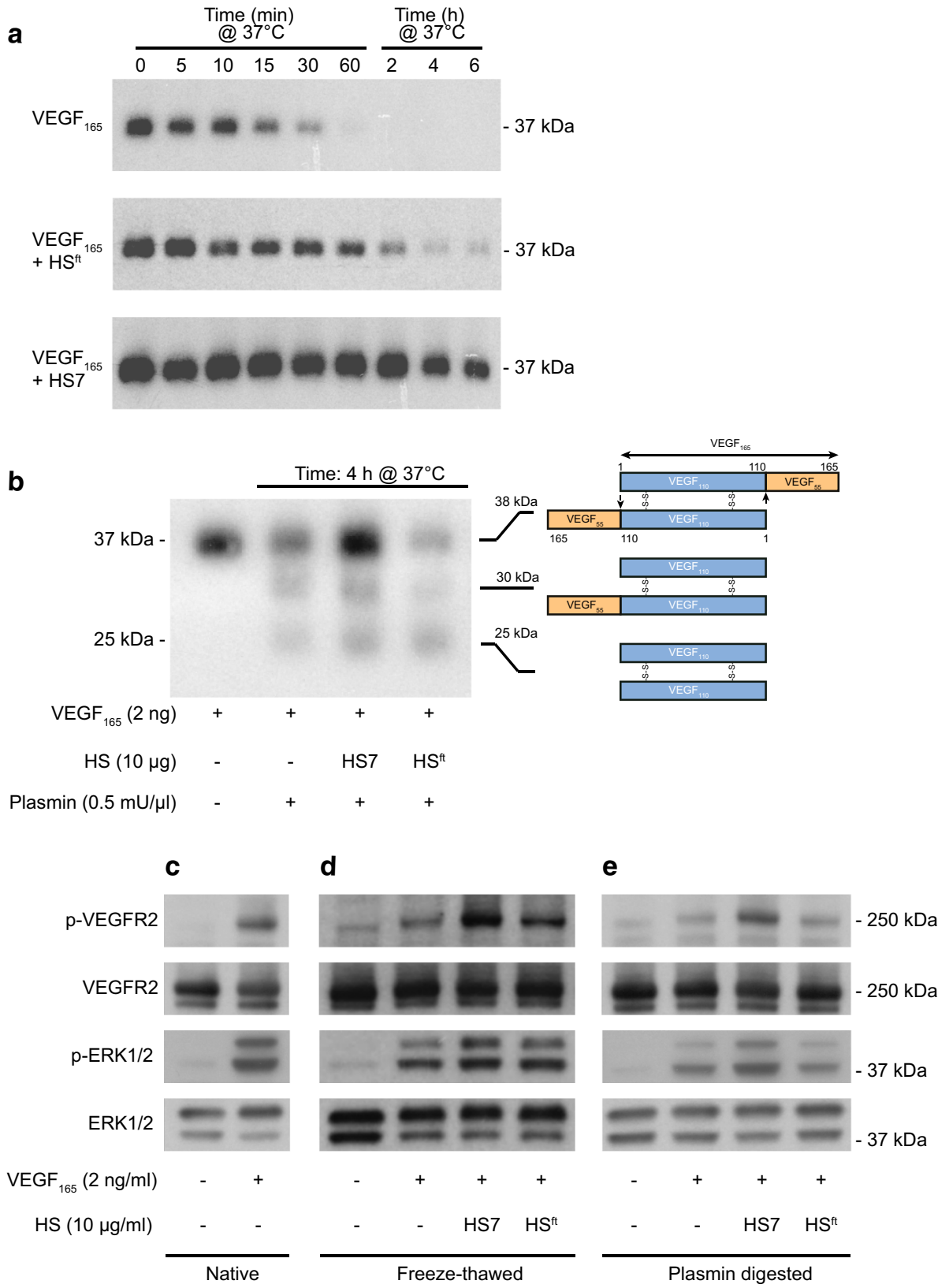

f

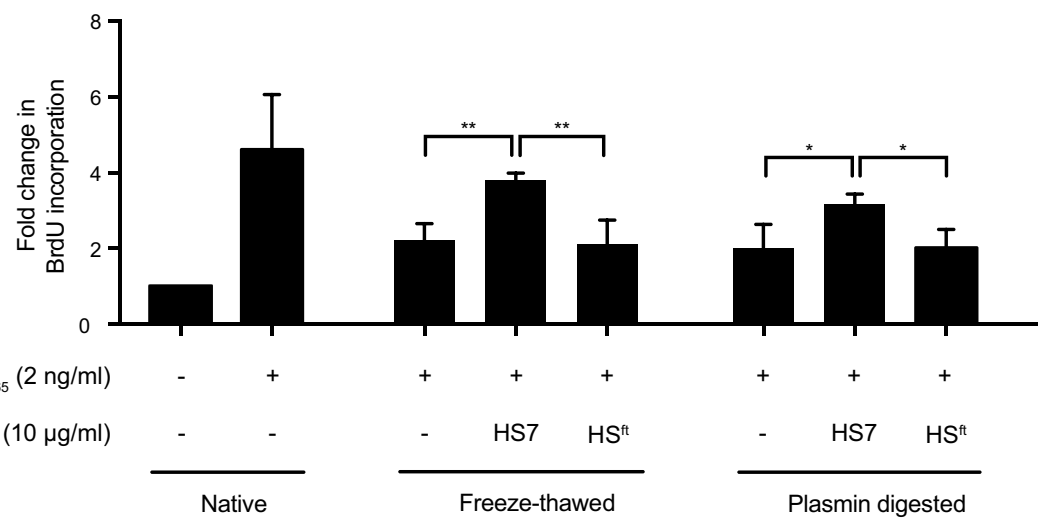




\section{Binding of HS7 to VEGF ${ }_{165}$ in serum}

The in vivo environment is rich with plasma serum proteins that could potentially disrupt the interaction of HS7 with its targeted growth factor. Therefore, HS7 or $\mathrm{HS}^{\mathrm{ft}}$ was used as an HS-tagged affinity-column to determine its affinity for VEGF $_{165}$ in serum. FBS was used to simulate the in vivo condition. As the amount of BMP-2 and VEGF $_{165}$ was low in FBS, we added exogenous BMP-2 and VEGF $_{165}$ prior to the start of the affinity capture. Figure $2 \mathrm{a}$ depicts silver-stained gel images of FBS with BMP-2 and VEGF 165 added, and the corresponding immunoblots (Fig. 2a).

Figure $2 b$ shows representative images of BMP- 2 and VEGF $_{165}$ eluted under high salt conditions of $1 \mathrm{~mol} / \mathrm{L} \mathrm{NaCl}$, and its corresponding densitometry analysis (ImageStudio Lite Version 5.2.5). The amount of $\mathrm{VEGF}_{165}$ eluted from the $\mathrm{HS}^{\mathrm{ft}}$-affinity capture column was low, compared to VEGF 165 eluted from the HS7-tagged affinity column. Densitometry revealed that $\mathrm{HS}^{\mathrm{ft}}$ has low affinity for $\mathrm{VEGF}_{165}$ in FBS, while it bound to the HS7-tagged column with higher affinity (Fig. 2b). A replicate experiment demonstrated similar findings (Fig. S1).

\section{Recovery from limb ischaemia}

The efficacy of HS7 as a therapeutic for blood vessel repair was tested in a clinically relevant, peripheral vascular disease model. As summarised in the timeline (Fig. 3a), we ligated the external iliac artery in the right limb of C57BL/6N mice and confirmed successful ligation by LDI (Fig. 3b, Day 0 Post-surgery) and MRA (Fig. 4a, Day 1 Post-surgery), before the start of treatment. Saline, HS7 (3 or $30 \mu \mathrm{g}$ ) or
$\mathrm{HS}^{\mathrm{ft}}(30 \mu \mathrm{g})$ were delivered via daily intramuscular injection for one week post-surgery. Recovery was monitored over 3 weeks by LDI and MRA (Fig. 3a). Representative LDI taken of the plantar foot is presented in Fig. $3 \mathrm{~b}$ as a time series. Representative reconstructed images of blood volume taken by MRA on day 8 are depicted in Fig. 4 a.

After receiving intramuscular injections daily for 1 week post-surgery, revascularization was observed in all groups by both LDI (Fig. 3b) and MRA (Fig. 4a). However, the extent and rate of recovery observed varied across the treatment groups. Blood perfusion to the plantar foot measured by LDI showed the greatest change up to 3 days post-surgery. Although the recovery in blood perfusion at subsequent time points was gradual, treatment with $30 \mu \mathrm{g}$ of HS7 consistently gave the highest change in blood perfusion compared to saline vehicle or $\mathrm{HS}^{\mathrm{ft}}$ (Fig. $3 \mathrm{c} ; * * p<0.01, * * * p<0.001$ ). This indicated that while the rate of recovery was continuous in all animals, reperfusion was enhanced in HS7-treated animals.

Blood volume in the ischaemic limb also showed a similar recovery response as seen with blood perfusion. Day 8 angiograms revealed the presence of bright signals in the ligated limb indicating blood flow (Fig. 4a), compared to their absence from angiograms taken at day 1 post-surgery. Animals treated with HS7 had greater signals associated with the ligated hindlimb, which translated into higher volumes of blood present (Fig. 4a). This was most evident when blood volume was compared to post-surgery blood volume on day 1 (Fig. 4b). Regardless of treatment received, the greatest change in blood volume measured in the ligated limb was between days 1 and 8 , after which no further increase was observed at any subsequent time point

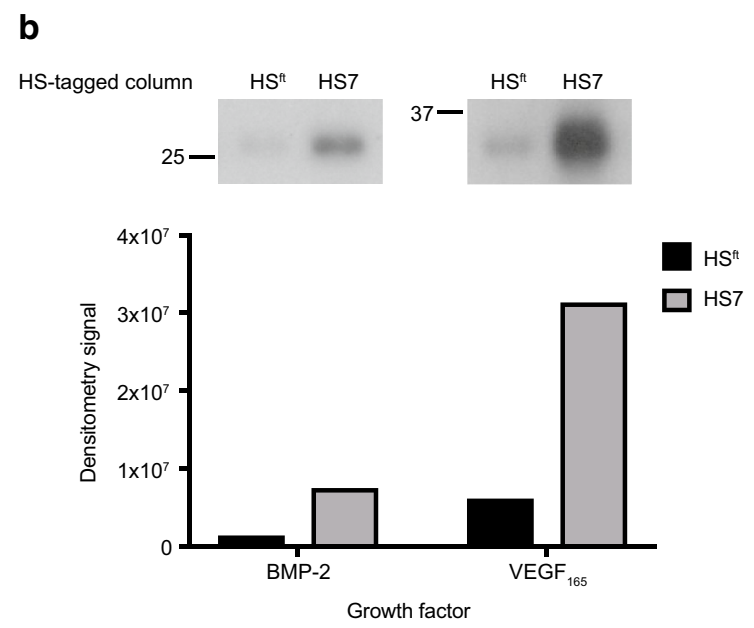

sponded to the respective immunoblots at similar molecular weights. b Representative immunoblot of BMP-2 and VEGF $_{165}$ eluted from $\mathrm{HS}^{\mathrm{ft}}$-tagged or HS7-tagged affinity columns and its corresponding densitometry analysis (performed on ImageStudio Lite Version 5.2.5)
Fig. 2 Elution of $\mathrm{VEGF}_{165}$ from HS-tagged columns a Silver-stained gel image and corresponding immunoblot of BMP-2 or VEGF 165 containing FBS from a single experiment. The addition of BMP-2 or VEGF $_{165}$ to FBS (denoted by ' + ') showed a band at approximately 25 and $37 \mathrm{kDa}$ on the silver-stained gel, respectively, which corre- 


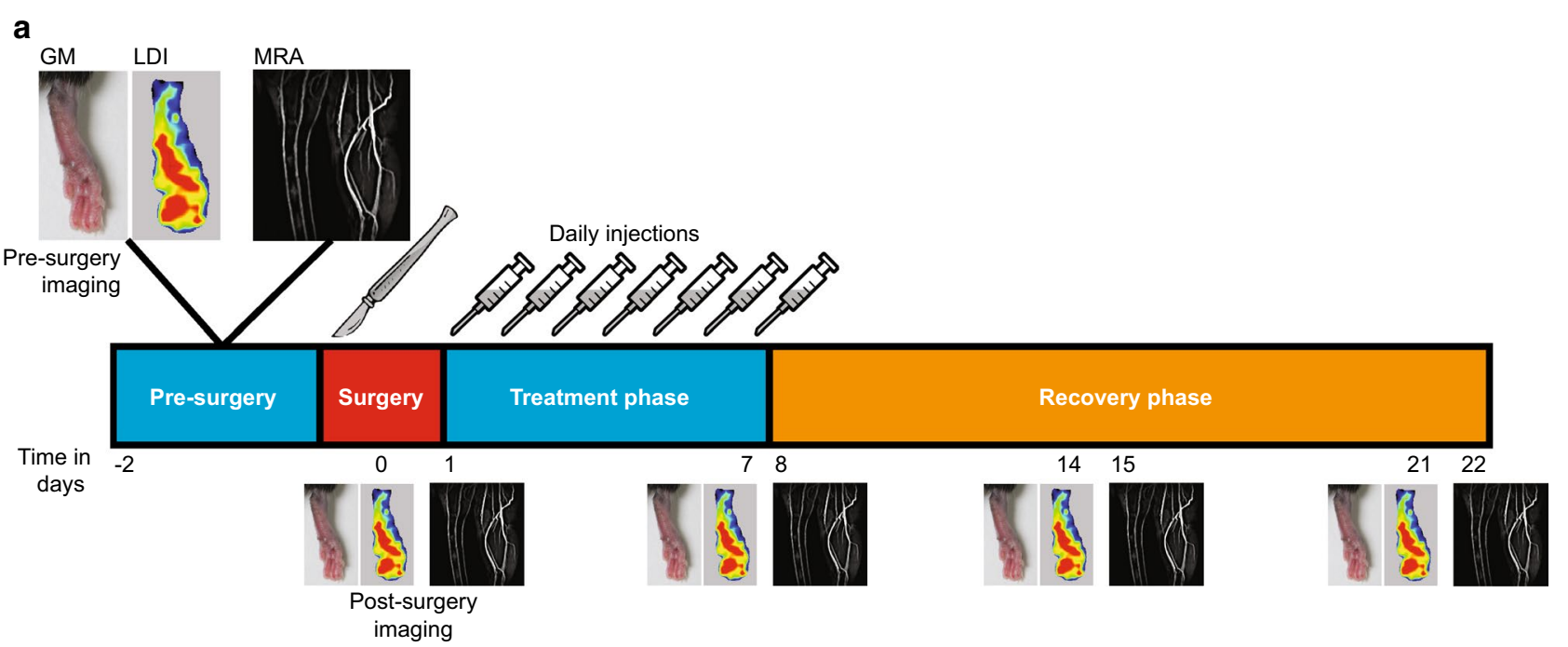

b
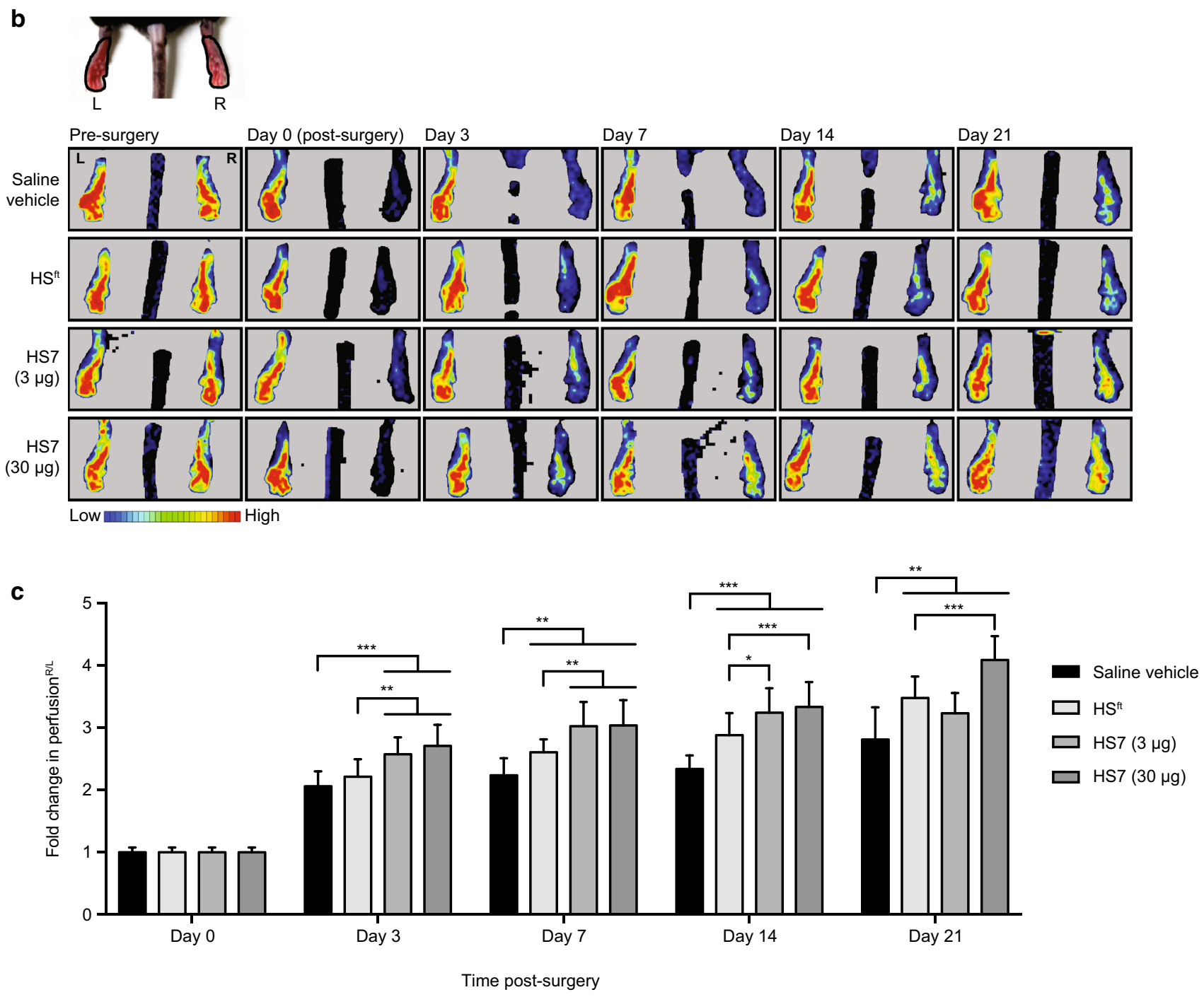
4Fig. 3 Time-line of study and LDI scanning a Time-line of in vivo study. GM gross morphology, LDI laser Doppler imaging, MRA magnetic resonance angiography. $\mathbf{b}$ The lower limbs of a mouse in a prone position were shown, with the left $(\mathrm{L})$ and right $(\mathrm{R})$ plantar feet indicated. Laser Doppler images shown follow this orientation. Presurgery, blood perfusion in both the left and right feet were similar, in contrast to post-surgery when blood perfusion to the right foot was obstructed. The time series showed the recovery of blood perfusion to the right foot. $\mathbf{c}$ Fold-change in blood perfusion normalised to day 0 (post-surgery). Two-way ANOVA with Tukey's multiple comparisons test was performed $\left({ }^{*} p<0.05 ; * * p<0.01 ; * * * p<0.001\right)$

across all groups (Fig. 4b). A comparison of the recovery rate across treatment groups, however, showed that animals treated with HS7 had the greatest change in blood volume $(* * * p<0.001)$. Treatment with HS7 led to a 13- to 20-foldchange in blood volume from day 1 to 8 post-surgery, which was two- to fourfold higher than treatment with saline vehicle or $\mathrm{HS}^{\mathrm{ft}}$ (Fig. 4b; ***p<0.001).

To determine any correlation between the blood volume re-established in the hindlimb and recovery of function, we utilised a functional recovery score index (Table 1) modified from a model described by Aitsebaomo et al. [24]. All animals were observed on Days 3, 7, 14 and 21 for functional use of the limb and plantar foot. Three animals in the $3 \mu \mathrm{g}$ treatment group and one animal in the $30 \mu \mathrm{g}$ treatment group were removed due to the presence of abrasions on their plantar foot that hampered normal functional recovery. The data showed that mice treated with HS7 recovered functional use of the ischaemic limb more rapidly compared to those treated with saline or $\mathrm{HS}^{\mathrm{ft}}$ (Fig. 5a, b). On day 3, when the animals were still receiving their daily treatments, those in the HS7 groups showed increased restoration of function in their ligated limb. By day 7, which coincided with the last day of therapy, two mice receiving the highest amount of HS7 demonstrated full functional use of the ligated limb. In comparison, mice receiving saline or $\mathrm{HS}^{\mathrm{ft}}$ had greatly reduced functional recovery in the affected limb. This observation was maintained throughout the study. The variability in functional recovery at day 21 across the various treatment groups was also assessed (\% coefficient of variation) (Fig. 5c). The data show that treatment with HS7 coupled high precision with low variability $(\% \mathrm{CV}=0.0)$ in outcome compared to the increased variability resulting from treatment with vehicle $(\% \mathrm{CV}=21.76)$ or $\mathrm{HS}^{\mathrm{ft}}(\% \mathrm{CV}=14.24)$ (Fig. 5c). Also, the percentage of animals that achieved full functional recovery was consistently higher from day 7 in animals treated with HS7, compared to saline vehicle or $\mathrm{HS}^{\mathrm{ft}}$ (Fig. 5d).

The largest response in blood volume was observed on day 8 , which coincided with the end of the treatment period. We performed an immunohistological analysis at this time point by staining for von Willebrand factor, a marker for endothelial cells that line the lumen of blood vessels, so enumerating the number of $\mathrm{vWF}^{+}$vessels per $\mathrm{mm}^{2}$ in each muscle group (Fig. 6). The data were further stratified into two groups based on a threshold relative to the highest vessel density in the control group. The data showed that irrespective of the muscle group, ischaemic limbs treated with HS7 $(30 \mu \mathrm{g})$ consistently had significant increases in the number of blood vessels compared to treatment with either saline or $\mathrm{HS}^{\mathrm{ft}}$. Notably, treatment with $\mathrm{HS}^{\mathrm{ft}}$ was comparable to the vehicle, except for two of the animals that had a slightly higher number of $\mathrm{vWF}^{+}$vessels in the gastrocnemius muscle; however, this was still lower than treatment with HS7 (Fig. 6). In general, ischaemic sites treated with HS7 at $3 \mu \mathrm{g}$ trended lower in $\mathrm{vWF}^{+}$vessel number compared to those treated with $30 \mu \mathrm{g}$, except in the gastrocnemius muscle, where it was comparable.

Consistent with previous studies [25], our data showed that tissues in the lower extremity were most affected by PAD. We therefore further quantified the number of regenerating myofibres in the gastrocnemius muscle. We chose to examine responses to HS7 (30 $\mu \mathrm{g})$ because the recovery of these animals was consistently higher than the other groups tested. The data showed that regenerating myofibres, characterised by centrally located nuclei [21], trended higher in their numbers in the HS7 group compared to saline controls (Fig. S2), further substantiating the positive effects observed with HS7 treatment. The number of $\alpha \mathrm{SMA}^{+}$-vessels in the quadriceps was also 1.65-fold higher in the HS7 group (Fig. $\mathrm{S} 3, * p<0.05)$.

\section{Discussion}

In this study, we demonstrate that treatment of ischaemic limbs with a blood vessel ECM-mimicking HS variant (HS7), one that avidly binds $\mathrm{VEGF}_{165}$, can accelerate subsequent revascularization and functional recovery. This particular HS7 variant was purified from HS $^{\mathrm{pm}}$ via affinitychromatography targeting the heparin-binding domain of $\mathrm{VEGF}_{165}$.

VEGF $_{165}$ is the most abundant isoform in its family and exists as a homodimer in vivo. When the homodimer binds two copies of its receptor, VEGF receptor-2, angiogenesis is initiated. Thus, maintaining the stability of the $\mathrm{VEGF}_{165}$ homodimer is central to unlocking the therapeutic effects of this potent angiogenic growth factor. Moreover, achieving this by targeting endogenously produced ligands represents a novel means of regulating the body's angiogenic cascade. Data from the in vitro study demonstrate that HS7 binds and sustains homodimeric $\mathrm{VEGF}_{165}$ for up to $6 \mathrm{~h}$, whereas complexation with a low-affinity binding HS variant $\left(\mathrm{HS}^{\mathrm{ft}}\right)$ did not improve the stability of the homodimer. That is, an HS variant with increased affinity for a particular growth factor can enhance the growth factor's 
a
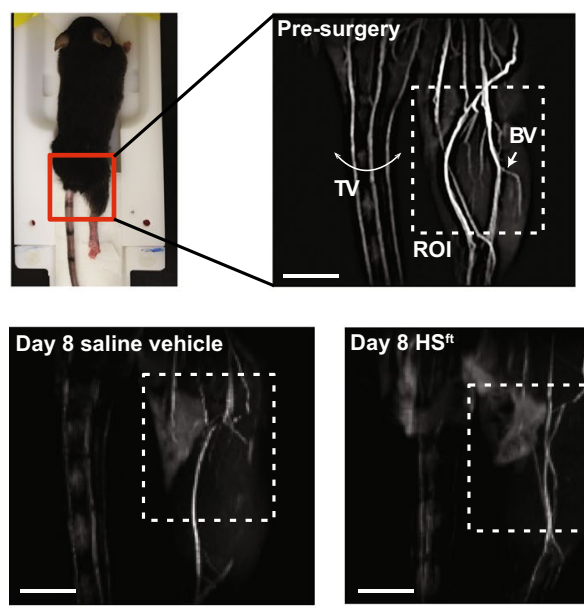

Low $\square$ High
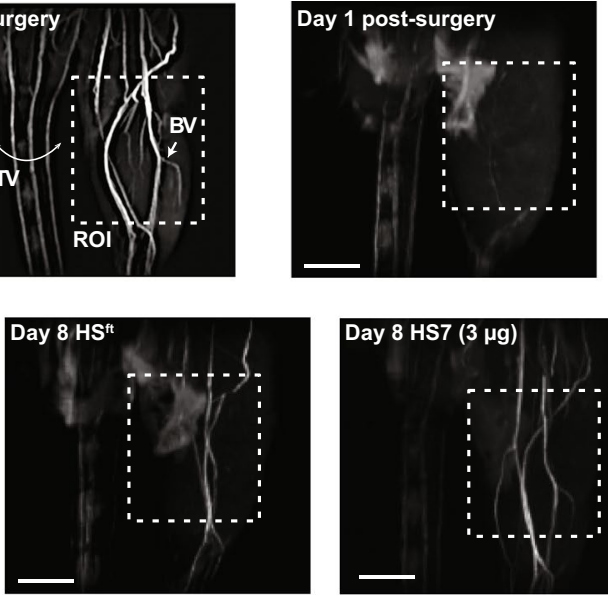

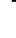

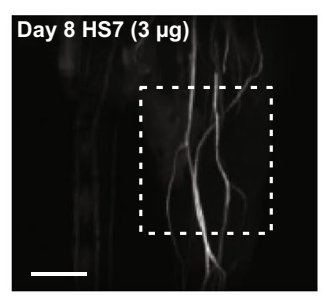

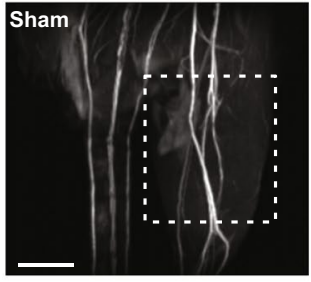

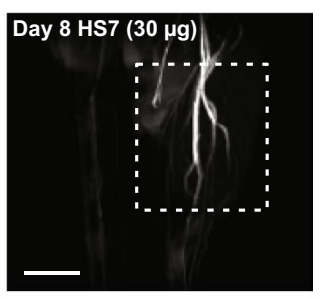

Scale bar: $4 \mathrm{~mm}$

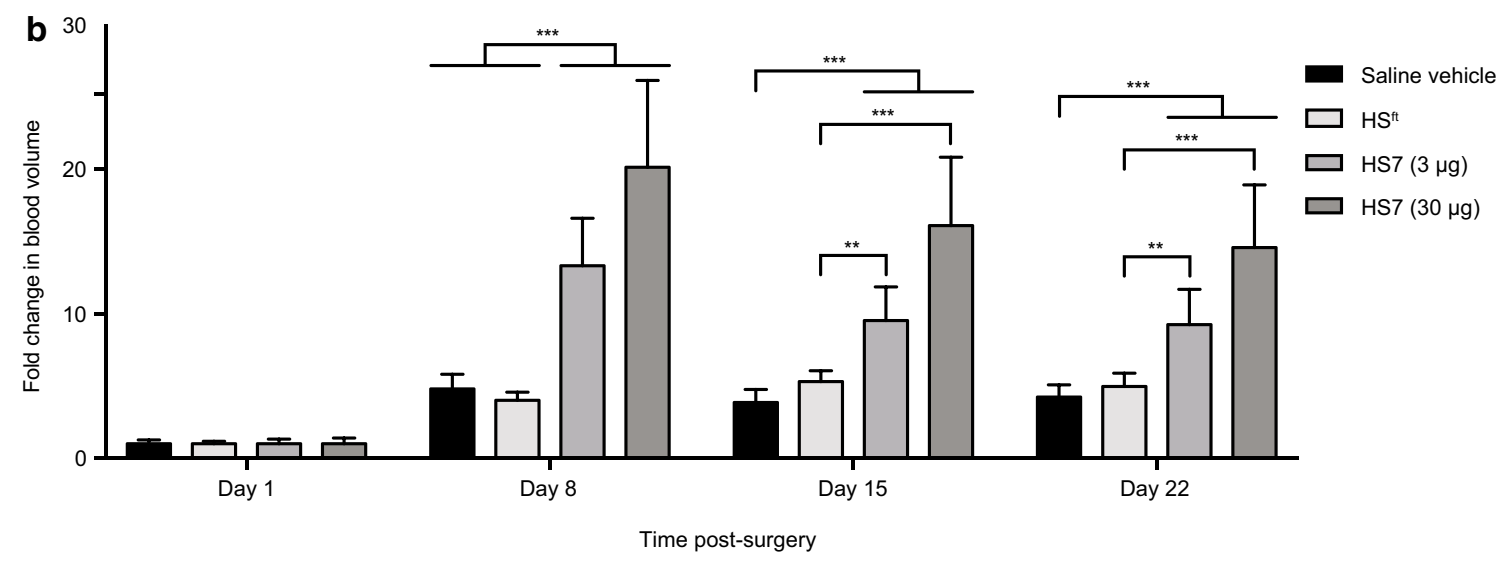

Fig. 4 Magnetic resonance angiography a An image of a mouse in a prone position on a cradle was shown. The red box delineates the region of the hindlimb that was imaged. Reconstructed MRA images obtained before and post-surgery confirmed the loss of blood flow following external iliac artery ligation. Reconstructed MRA images of sham-operated mice showed no difference from pre-surgery. Representative reconstructed MRA images of mice are shown after a

bioactivity. Similar increased stability in FGF-2 (fibroblast growth factor-2) [26] and VEGF [19] has been observed in the presence of heparin, a highly sulphated form of HS [27]; however, due to its powerful anticoagulant activity [28], the administration of heparin raises strong concerns about associated bleeding [29], let alone its myriad of ancillary, adverse clinical reactions. Heparin-bonded bypasses, or stent grafts for below-knee bypasses, have also brought about heparin-induced thrombocytopenia in patients [30]. Furthermore, while the high sulphation of heparin affords the ability to bind and stabilise a broad range of proteins, its propensity for indiscriminate binding also carries the substantial risk of activating various off-target biological processes, so leading to unfavourable healing outcomes. week of treatment (day 8). High blood flow is depicted by bright signals and low blood flow is depicted by dark signals. $T V$ tail vein, $B V$ blood vessel, $R O I$ region of interest of blood volume quantification. $\mathbf{b}$ Fold-change in blood volume in the ischaemic hindlimb. Blood flow was measured by MRA and normalised to day 1 post-surgery levels. Two-way ANOVA with Tukey's multiple comparisons test was performed $(* * p<0.01 ; * * * p<0.001)$

In addition to thermal stability, studies in vitro show that HS7 also reduced VEGF $_{165}$ susceptibility to proteolysis by plasmin, an enzyme present in injured tissue that plays several roles during angiogenesis, including the release of ECM proteins, activation of matrix metalloproteinases and modulating the availability of major angiogenic growth factors. VEGF-induced angiogenesis in plasminogen-deficient mice is known to be compromised, for example [31]. However, VEGF $_{165}$ is also susceptible to plasmin, with a resultant reduction in its mitogenic activity by the removal of its heparin-binding domain [32]. Our results demonstrate that HS7 reduced $\mathrm{VEGF}_{165}$ susceptibility to plasmin, reemphasizing the importance of the heparin-binding domain of $\mathrm{VEGF}_{165}$ for its angiogenic activity, as others have previously indicated $[23,32,33]$. 


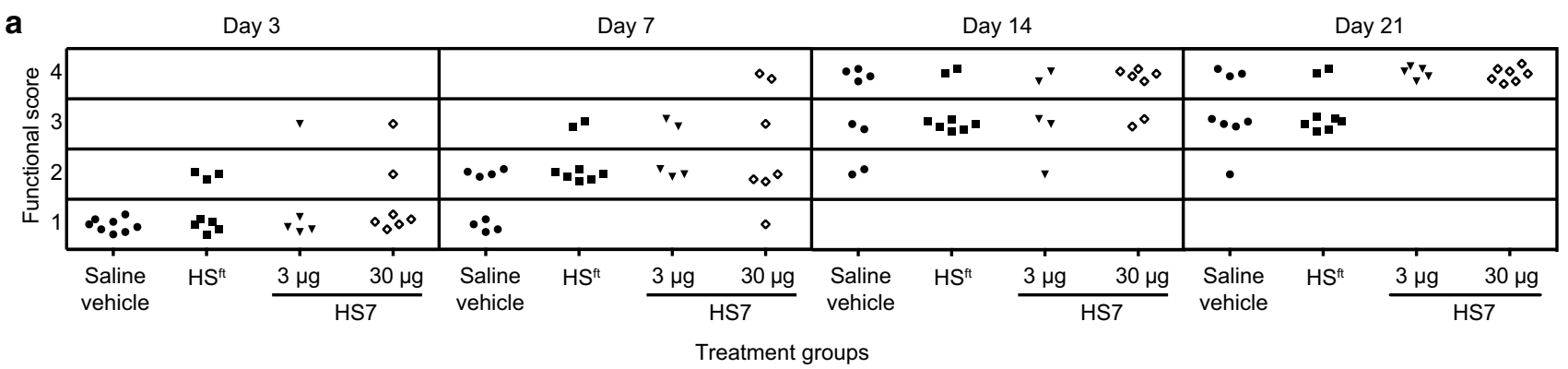

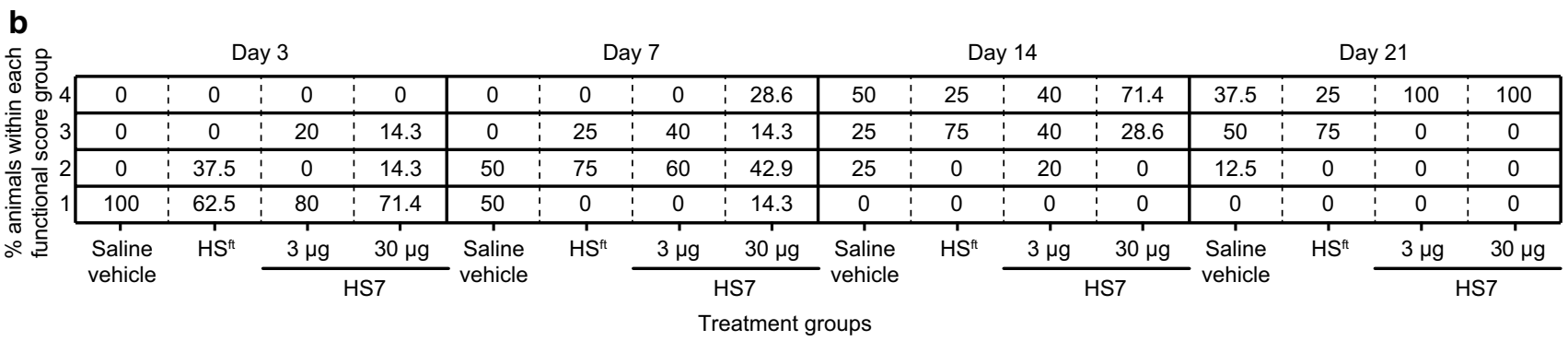

C

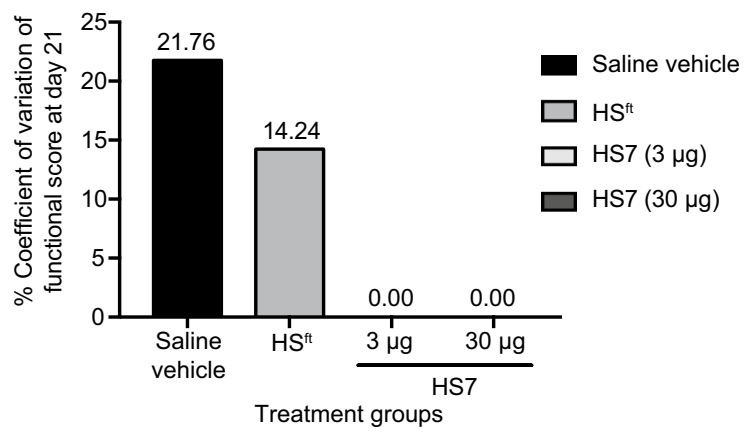

Fig. 5 Ischaemic limb function scored on days 3, 7, 14 and 21 a Each symbol represents one animal in a scatter plot, which is represented numerically in $\mathbf{b}$ as percentage of animals. Animals were removed from the HS7 treatment groups if any abnormal abrasions hindered

Our previous report showed that HS7 alone was not able to stimulate endothelial cell proliferation [18], thus making the selection of C57BL/6 mice for this proof-of-concept study crucial [9]. Also, the period of treatment coincided with the time-frame when VEGF is stably detected in the ligated tissue [9]. Based on our MRA data, even $3 \mu \mathrm{g}$ of HS7 was sufficient to boost blood flow in the ischaemic limb and increase $\mathrm{vWF}^{+}$vessel number by day 8 . It was, however, insufficient to recover perfusion in the plantar foot as well as $30 \mu \mathrm{g}$ of HS7. This appears to represent a dose-response criterion that has to be considered for future trials. The observation of more regenerating myofibres and $\alpha \mathrm{SMA}^{+}$-vessels after only one week of treatment with HS7 was encouraging as it indicated that HS7 delivery could promote the recovery that was subsequently observed in our functional assessments of limb usage (Fig. 5). The d

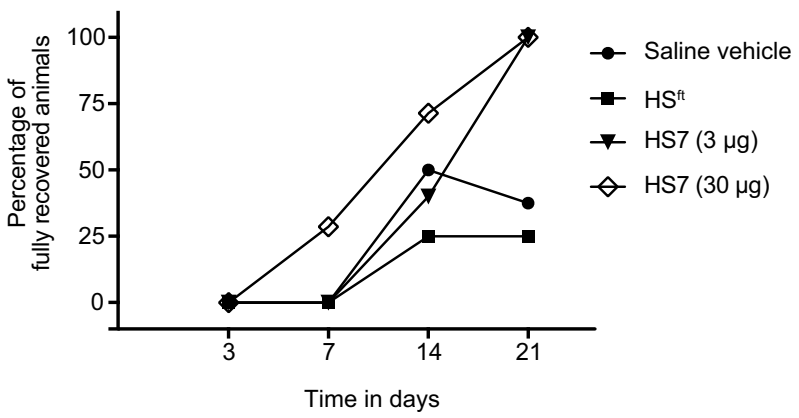

normal functional recovery. $\mathbf{c}$ Percentage coefficient of variation of the functional score on day 21. d Percentage of animals that showed full recovery (having a score of 4) on days 3, 7, 14 and 21

presence of more $\alpha \mathrm{SMA}^{+}$-vessels indicated the presence of mature vessels that could contribute to the higher blood flow quantified in HS7-treated animals. The comparison of $\mathrm{HS}^{\mathrm{ft}}$ treatment outcomes was of particular interest. Based on our in vitro findings, $\mathrm{HS}^{\mathrm{ft}}$ had much reduced stabilising effects on VEGF 165 . This might explain the minimal effect $\mathrm{HS}^{\mathrm{ft}}$ had on accelerating blood reperfusion in the ischaemic limb, even though its interaction with other angiogenic factors upregulated during ischaemia seems highly likely. Recovery from ligation was similar to the saline group and could represent the normal rate of blood flow recovery that occurs in C57BL/6 mice $[34,35]$. A concern with the use of HS7 as a treatment for vascular ischaemia was the potential for HS7 to bind to a host of other proteins in vivo via electrostatic interaction, or for proteins in serum to disrupt the HS7VEGF $_{165}$ interaction. Therefore, we deemed it encouraging 

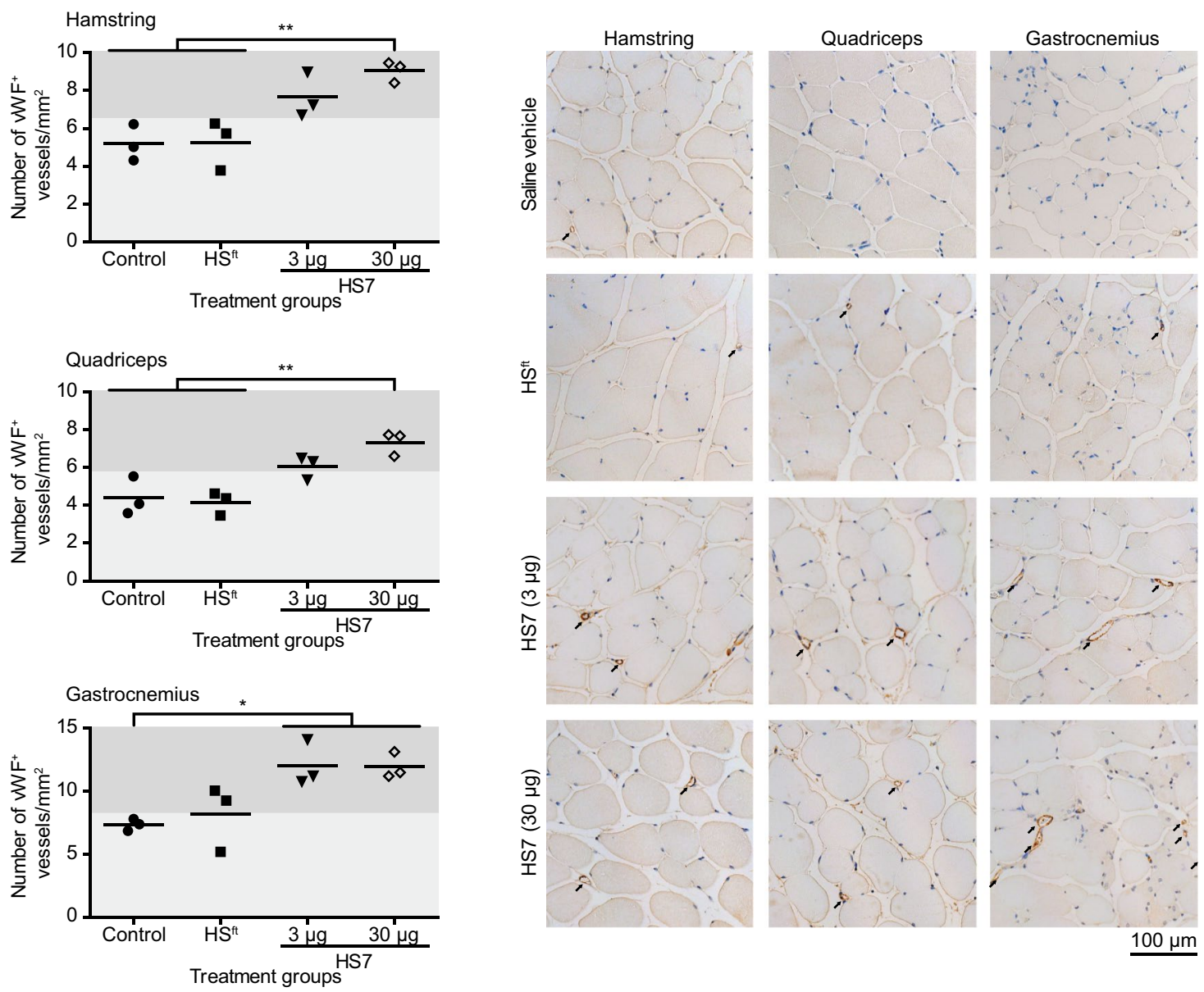

Fig. 6 Histological assessments on hindlimb tissues harvested on day 8 . The number of von Willebrand factor-stained vessels seen in cross section was counted from six random fields of view from images captured under brightfield using the Metafer 4 automated capture system and presented as mean number \pm standard deviation per square millimetre $\left(\mathrm{mm}^{2}\right)$. Representative cross-sectional images from hamstring,

when affinity-chromatography of FBS pre-loaded with both BMP-2 and VEGF 165 demonstrated that HS7-tagged columns had a higher affinity for $\operatorname{VEGF}_{165}$ (Fig. 2b). This confirmed that the HS7-VEGF 165 interaction was maintained despite the presence of proteins in serum that could potentially hinder this interaction. Such data lend support to our hypothesis that HS7 was able to bind and potentiate the endogenous ligands like $\mathrm{VEGF}_{165}$ to promote reperfusion recovery. However, while the HS7-column bound more VEGF $_{165}$ by virtue of its increased affinity for the growth factor, it does not answer the question of whether they colocalise in vivo, which necessitates further investigations.

Recent reports have highlighted the possibility of HSactivating Toll-like receptor 4 , so promoting inflammatory events that could initiate angiogenesis at ischaemic sites [36, 37]. Indeed, inflammation is observed in patients suffering from critical limb ischaemia with underlying atherosclerotic quadriceps and gastrocnemius are shown. For display purposes, representative images captured on ZEISS AxioImager Z1 were adjusted uniformly to increase the contrast of the reddish-brown stains on ImageJ. Arrows identify vessels positive for von Willebrand factor. Scale bar $=100 \mu \mathrm{m} .(* p<0.05 ; * * p<0.01)$

pathology [38]. However, our SPR data revealed no interaction between TLR4 and heparin (Fig. S4a) immobilised on a SA chip support, in contrast with the experiments that showed $\mathrm{VEGF}_{165}$ binding to immobilised heparin in a dosedependent manner. Incubation of RAW264.7 with HS also showed that the TLR4 signal transduction pathway was not activated, whereas phosphorylation was observed when cells were exposed to LPS as a positive control (Fig. S4b).

The use of HS on its own for the treatment of limb ischaemia is in contrast to studies investigating gene-, protein- or cell-based treatments for therapeutic angiogenesis in similar animal models [34, 39-41]. The assumptions of such studies still rely on increasing the local concentration of angiogenic growth factors to stimulate neovascularization. In contrast, similar studies in cutaneous wounds [42] and pressure ulcers [43] in rats using the HS glycosaminoglycan mimetic OTR4120 support the finding that external applications of 
HS potentiate the endogenous healing capacity of tissues experiencing damage. The administration of another synthetic glycosaminoglycan, OTR4131, accelerated neovascularization in rat limb ischaemia as well as muscle regeneration [44]. These and other studies postulated that the binding of synthetic glycosaminoglycans to VEGF might potentiate the growth factor's angiogenic activity [45] through a combination of mechanisms shown by our in vitro assays in the current report, as well as from past investigations [18]. We show here that HS7 prolongs the active, dimeric VEGF $_{165}$ for a longer period than the low-affinity $\mathrm{HS}^{\mathrm{ft}}$ or in its absence. Also, the use of an affinity-tuned HS to enhance the activity of VEGF 165 should decrease the risk of off-target effects of HS, as seen in the case of heparin, which binds non-discriminately to a large number of proteins. Synthetic glycosaminoglycans may replace endogenous HS species that are degraded in wound sites, but they presumably bind a large number of factors, including agonists and antagonists, unless they are carefully filtered. Naturally occurring HS species carry targeted binding motifs that synthetic GAGs cannot fully mimic.

Using a murine hindlimb ischaemia model, we showed that HS7 improved blood flow recovery. Despite the positive outcomes, we recognise the inherent limitations of the study. One of them is the use of 10 -week old C57BL/6N mice, which is akin to replicating the presence of active repair cascades that occur in young, healthy adolescents or adults [46]. PAD and critical limb ischaemia are more prevalent in aged and unhealthy populations, such as patients with diabetes $[47,48]$. It is therefore crucial that the efficacy of HS7 is further validated in animals models with accompanying comorbidities [46]. For HS7 to be a suitable therapeutic agent, amounts of endogenous VEGF expression in the patient become crucial. Healing capacity is observed to decrease with age in a mouse wound model, due to reduced gene expression of growth factors and their receptors [49]. The combined delivery of VEGF 165 and HS7 may still be required in some patients. HS7 stabilisation of ligands also offers the additional advantage of reducing the high doses of exogenous growth factor required, providing a possible solution to the side effects that accompany the use of growth factors in revascularization therapy.

Acknowledgements We are thankful to Dr. Anna Blocki, Yingting Wang, and Dr. Sakthivel Sekar (Singapore Bioimaging Consortium, A*STAR) for technical assistance in performing limb surgeries and using the Bruker Biospec 9.4T Bruker scanner; Declan Patrick Lunny (Institute of Medical Biology, A*STAR) for technical assistance with immunohistology protocols; Reyhan Arisoy (PERIMED, Sweden) for assistance with LDI; Sarah Binte Zulkifli (IMB Microscopy Unit, Institute of Medical Biology) for assistance with slide scanning with Metafer 4 system; Prof. Theo Kofidis (Dept. of Surgery, Yong Loo Lin School of Medicine, National University of Singapore) for technical expertise on interpretation of data; and Prof. Michael Raghunath
(Departments of Biomedical Engineering and Biochemistry, National University of Singapore) for advice and access to equipment for LDI.

Author contributions SP conceptualised and planned the study, designed and performed experiments, designed and performed animal study (which included performing limb surgeries, treatment administration and collection of imaging data), analysed data, and wrote the manuscript; XL performed in vitro experiments and analysed histology data; RAAS performed in vitro experiments; JPH and KB conceived and oversaw the research; VN and SMC conceived the study, oversaw the research and edited the manuscript.

Funding This work is funded by an A*STAR Joint Council Office 13th JCO Project Grant 1431A064.

\section{Compliance with ethical standards}

Conflict of interest Authors declare they have no competing interests.

Open Access This article is distributed under the terms of the Creative Commons Attribution 4.0 International License (http://creativeco mmons.org/licenses/by/4.0/), which permits unrestricted use, distribution, and reproduction in any medium, provided you give appropriate credit to the original author(s) and the source, provide a link to the Creative Commons license, and indicate if changes were made.

\section{References}

1. Fowkes FG, Rudan D, Rudan I et al (2013) Comparison of global estimates of prevalence and risk factors for peripheral artery disease in 2000 and 2010: a systematic review and analysis. Lancet 382:1329-1340. https://doi.org/10.1016/S0140-6736(13)61249-0

2. DeRubertis BG, Faries PL, McKinsey JF et al (2007) Shifting paradigms in the treatment of lower extremity vascular disease: a report of 1000 percutaneous interventions. Ann Surg 246:414415. https://doi.org/10.1097/SLA.0b013e31814699a2

3. Cooke JP, Losordo DW (2015) Modulating the vascular response to limb ischemia: angiogenic and cell therapies. Circ Res 116:1561-1578. https://doi.org/10.1161/CIRCRESAHA .115 .303565

4. Godman CA, Chheda KP, Hightower LE et al (2010) Hyperbaric oxygen induces a cytoprotective and angiogenic response in human microvascular endothelial cells. Cell Stress Chaperones $15: 431-442$

5. Fadini GP, Agostini C, Avogaro A (2010) Autologous stem cell therapy for peripheral arterial disease meta-analysis and systematic review of the literature. Atherosclerosis 209:10-17. https:// doi.org/10.1016/j.atherosclerosis.2009.08.033

6. Marui A, Tabata Y, Kojima S et al (2007) A novel approach to therapeutic angiogenesis for patients with critical limb ischemia by sustained release of basic fibroblast growth factor using biodegradable gelatin hydrogel: an initial report of the phase I-IIa study. Circ J 71:1181-1186

7. de Souza Lins Borba FK, Felix GLQ, Costa EVL et al (2016) Fractal analysis of extra-embryonic vessels of chick embryos under the effect of glucosamine and chondroitin sulfates. Microvasc Res 105:114-118. https://doi.org/10.1016/j.mvr.2016.02.005

8. Ferrara N, Gerber HP, LeCouter J (2003) The biology of VEGF and its receptors. Nat Med 9:669-676. https://doi.org/10.1038/ nm0603-669 
9. Couffinhal T, Silver M, Zheng LP et al (1998) Mouse model of angiogenesis. Am J Pathol 152:1667-1679

10. Takeshita S, Zheng LP, Brogi E et al (1994) Therapeutic angiogenesis. A single intraarterial bolus of vascular endothelial growth factor augments revascularization in a rabbit ischemic hind limb model. J Clin Invest 93:662-670. https://doi.org/10.1172/JCI11 7018

11. Rajagopalan S, Mohler ER 3rd, Lederman RJ et al (2003) Regional angiogenesis with vascular endothelial growth factor in peripheral arterial disease: a phase II randomized, double-blind, controlled study of adenoviral delivery of vascular endothelial growth factor 121 in patients with disabling intermittent cl. Circulation 108:1933-1938. https://doi. org/10.1161/01.CIR.0000093398.16124.29

12. Eppler SM, Combs DL, Henry TD et al (2002) A target-mediated model to describe the pharmacokinetics and hemodynamic effects of recombinant human vascular endothelial growth factor in humans. Clin Pharmacol Ther 72:20-32. https://doi. org/10.1067/mcp.2002.126179

13. Manning MC, Patel K, Borchardt RT (1989) Stability of protein pharmaceuticals. Pharm Res 6:903-918

14. Kaminski KA, Bonda TA, Korecki J, Musial WJ (2002) Oxidative stress and neutrophil activation-the two keystones of ischemia/reperfusion injury. Int J Cardiol 86:41-59

15. Carragee EJ, Ghanayem AJ, Weiner BK et al (2011) A challenge to integrity in spine publications: years of living dangerously with the promotion of bone growth factors. Spine J 11:463-468. https://doi.org/10.1016/j.spinee.2011.06.001

16. van Wijk XM, van Kuppevelt TH (2014) Heparan sulfate in angiogenesis: a target for therapy. Angiogenesis 17:443-462. https://doi.org/10.1007/s10456-013-9401-6

17. Gitay-Goren H, Soker S, Vlodavsky I, Neufeld G (1992) The binding of vascular endothelial growth factor to its receptors is dependent on cell surface-associated heparin-like molecules. J Biol Chem 267:6093-6098

18. Wang C, Poon S, Murali S et al (2014) Engineering a vascular endothelial growth factor 165-binding heparan sulfate for vascular therapy. Biomaterials 35:6776-6786. https://doi. org/10.1016/j.biomaterials.2014.04.084

19. Brandner B, Kurkela R, Vihko P, Kungl AJ (2006) Investigating the effect of VEGF glycosylation on glycosaminoglycan binding and protein unfolding. Biochem Biophys Res Commun 340:836-839. https://doi.org/10.1016/j.bbrc.2005.12.079

20. Blocki A, Wang Y, Koch M et al (2015) Sourcing of an alternative pericyte-like cell type from peripheral blood in clinically relevant numbers for therapeutic angiogenic applications. Mol Ther 23:510-522. https://doi.org/10.1038/mt.2014.232

21. Folker ES, Baylies MK (2013) Nuclear positioning in muscle development and disease. Front Physiol 4:363. https://doi. org/10.3389/fphys.2013.00363

22. Didiasova M, Wujak L, Wygrecka M, Zakrzewicz D (2014) From plasminogen to plasmin: role of plasminogen receptors in human cancer. Int J Mol Sci 15:21229-21252. https://doi. org/10.3390/ijms 151121229

23. Lauer G, Sollberg S, Cole M et al (2002) Generation of a novel proteolysis resistant vascular endothelial growth factor 165 variant by a site-directed mutation at the plasmin sensitive cleavage site. FEBS Lett 531:309-313

24. Aitsebaomo J, Srivastava S, Zhang H et al (2011) Recombinant human interleukin-11 treatment enhances collateral vessel growth after femoral artery ligation. Arter Thromb Vasc Biol 31:306-312. https://doi.org/10.1161/ATVBAHA.110.216986

25. McDermott MM, Hoff F, Ferrucci L et al (2007) Lower extremity ischemia, calf skeletal muscle characteristics, and functional impairment in peripheral arterial disease. J Am Geriatr Soc 55:400-406. https://doi.org/10.1111/j.1532-5415.2007.01092.x
26. Gospodarowicz D, Cheng J (1986) Heparin protects basic and acidic FGF from inactivation. J Cell Physiol 128:475-484. https ://doi.org/10.1002/jcp.1041280317

27. Sarrazin S, Lamanna WC, Esko JD (2011) Heparan sulfate proteoglycans. Cold Spring Harb Perspect Biol 3:a004952. https:// doi.org/10.1101/cshperspect.a004952

28. Hirsh J, Anand SS, Halperin JL, Fuster V (2001) Guide to anticoagulant therapy: heparin. Circulation 103:2994-3018

29. Cossette B, Pelletier ME, Carrier N et al (2010) Evaluation of bleeding risk in patients exposed to therapeutic unfractionated or low-molecular-weight heparin: a cohort study in the context of a quality improvement initiative. Ann Pharmacother 44:994-1002. https://doi.org/10.1345/aph.1M615

30. Blas J-VV, Carsten CG, Gray BH (2016) Heparin-induced thrombocytopenia associated with a heparin-bonded stent graft. Ann Vasc Surg 33:227.e1-227.e4. https://doi.org/10.1016/j. avsg.2015.11.015

31. Oh CW, Hoover-Plow J, Plow EF (2003) The role of plasminogen in angiogenesis in vivo. J Thromb Haemost 1:1683-1687. https:// doi.org/10.1046/j.1538-7836.2003.00182.x

32. Keyt BA, Berleau LT, Nguyen HV et al (1996) The carboxylterminal domain (111-165) of vascular endothelial growth factor is critical for its mitogenic potency. J Biol Chem 271:7788-7795

33. Roth D, Piekarek M, Paulsson M et al (2006) Plasmin modulates vascular endothelial growth factor-A-mediated angiogenesis during wound repair. Am J Pathol 168:670-684. https://doi. org/10.2353/ajpath.2006.050372

34. Brenes RA, Jadlowiec CC, Bear M et al (2012) Toward a mouse model of hind limb ischemia to test therapeutic angiogenesis. J Vasc Surg 56:1669-1679. https://doi.org/10.1016/j. jvs.2012.04.067 (discussion 1679).

35. Scholz D, Ziegelhoeffer T, Helisch A et al (2002) Contribution of arteriogenesis and angiogenesis to postocclusive hindlimb perfusion in mice. J Mol Cell Cardiol 34:775-787

36. Brennan TV, Lin L, Huang X et al (2012) Heparan sulfate, an endogenous TLR4 agonist, promotes acute GVHD after allogeneic stem cell transplantation. Blood 120:2899-2908. https://doi. org/10.1182/blood-2011-07-368720

37. Fang W, Bi D, Zheng R et al (2017) Identification and activation of TLR4-mediated signalling pathways by alginate-derived guluronate oligosaccharide in RAW264.7 macrophages. Sci Rep 7:1663. https://doi.org/10.1038/s41598-017-01868-0

38. Barani J, Nilsson J-A, Mattiasson I et al (2005) Inflammatory mediators are associated with 1-year mortality in critical limb ischemia. J Vasc Surg 42:75-80. https://doi.org/10.1016/j. jvs.2005.03.025

39. Nakamura S, Takikawa M, Ishihara M et al (2012) Delivery system for autologous growth factors fabricated with low-molecularweight heparin and protamine to attenuate ischemic hind-limb loss in a mouse model. J Artif Organs 15:375-385. https://doi. org/10.1007/s10047-012-0658-0

40. Beegle JR, Magner NL, Kalomoiris S et al (2016) Preclinical evaluation of mesenchymal stem cells overexpressing VEGF to treat critical limb ischemia. Mol Ther Methods Clin Dev 3:16053. https://doi.org/10.1038/mtm.2016.53

41. Zhang JC, Zheng GF, Wu L et al (2014) Bone marrow mesenchymal stem cells overexpressing human basic fibroblast growth factor increase vasculogenesis in ischemic rats. Braz J Med Biol Res 47:886-894

42. Tong M, Tuk B, Hekking IM et al (2009) Stimulated neovascularization, inflammation resolution and collagen maturation in healing rat cutaneous wounds by a heparan sulfate glycosaminoglycan mimetic, OTR4120. Wound Repair Regen 17:840-852. https:// doi.org/10.1111/j.1524-475X.2009.00548.x

43. Tong M, Tuk B, Hekking IM et al (2011) Heparan sulfate glycosaminoglycan mimetic improves pressure ulcer healing in 
a rat model of cutaneous ischemia-reperfusion injury. Wound Repair Regen 19:505-514. https://doi.org/10.1111/j.1524475X.2011.00704.X

44. Chevalier F, Arnaud D, Henault E et al (2015) A fine structural modification of glycosaminoglycans is correlated with the progression of muscle regeneration after ischaemia: towards a matrixbased therapy? Eur Cells Mater 30:51-68

45. Rouet V, Hamma-Kourbali Y, Petit E et al (2005) A synthetic glycosaminoglycan mimetic binds vascular endothelial growth factor and modulates angiogenesis. J Biol Chem 280:32792-32800. https ://doi.org/10.1074/jbc.M504492200

46. Dragneva G, Korpisalo P, Yla-Herttuala S (2013) Promoting blood vessel growth in ischemic diseases: challenges in translating preclinical potential into clinical success. Dis Model Mech 6:312322. https://doi.org/10.1242/dmm.010413

47. American Diabetes A (2003) Peripheral arterial disease in people with diabetes. Diabetes Care 26:3333-3341

48. Huysman E, Mathieu C (2009) Diabetes and peripheral vascular disease. Acta Chir Belg 109:587-594

49. Komi-Kuramochi A, Kawano M, Oda Y et al (2005) Expression of fibroblast growth factors and their receptors during full-thickness skin wound healing in young and aged mice. J Endocrinol 186:273-289. https://doi.org/10.1677/joe.1.06055 